\title{
EL DEBER DEL MÉDICO Y EL DERECHO DEL ENFERMO
}

\author{
ANTONIO ROVIRA VIÑAS
}





\title{
EL DEBER DEL MÉDICO Y EL DERECHO DEL ENFERMO (*)
}

\author{
POR \\ ANTONIO ROVIRA VIÑAS
}

Podemos decir - $y$ es pacífico en la doctrina más asentada afirmar- que el derecho a la intimidad, el derecho a la vida privada, a la integridad física y moral y a la libertad ideológica, religiosa y de culto, son concreciones del derecho a la libertad, concreción que no sólo se reconoce en los textos constitucionales y en las declaraciones, sino que tiene antecedentes mucho más remotos, si no en todos, sí en gran número de países y ordenamientos jurídicos.

Con la positivación del derecho a la intimidad o a la vida privada, a la integridad física y moral, lo que se pretende es asegurar en mayor medida este ámbito privado, un ámbito de la persona en el que no se pueda intervenir, es decir, un ámbito en el cual la soberanía sobre el mismo es exclusivamente del titular del derecho.

No obstante, como todo derecho, tiene sus límites, límites que los podemos concretar en el mismo derecho de los demás y en la preferencia o prevalencia en algunos casos de bienes constitucionalmente protegidos, como puede ser el de la seguridad y salud pública.

No obstante, el derecho a la intimidad y el derecho a la libertad del individuo en su ámbito de vida privada ante el desarrollo de la medicina está generando procedimientos y técnicas que permiten incidir en este ámbito de soberanía individual sin que en muchos casos sea perceptible la intromisión. Es decir, está ocurriendo que la formulación del derecho a

(*) Este texto fue presentado en la 3.- Mesa Redonda de los Ombudsmen europeos, celebrada en Florencia los días 7 y 8 de noviembre de 1991. 
la intimidad e integridad moral del ciudadano, con las garantías y límites que hoy lo conforman, es insuficiente para prevenir las lesiones que a este derecho pueden venir por parte de las nuevas tecnologías.

Los nuevos avances en la medicina, con intervenciones que pueden hacer sobrevivir a una persona en circunstancias excepcionales, pueden afectar al contenido del derecho fundamental a la intimidad, a la integridad $o$ al honor, haciéndose necesaria cada vez en mayor medida la concreción de los límites y de las garantías que deben informar toda actuación médica en relación con las creencias o intimidad del ciudadano.

Ante eso, los juristas han intentado y están intentando concretar en mayor medida este ámbito, ya sea desarrollando a partir de él nuevos derechos $o$ introduciendo nuevos caracteres que permitan hacer frente a estos nuevos medios, limitándolos y prohibiéndolos cuando se pueda abusar de ellos.

Es decir, la salud, la vida, la libertad y en general los derechos fundamentales se transforman, como es sabido, en bienes no sólo individuales, sino también sociales, que el Estado debe asegurar aun a costa, en ocasiones, de limitar o incidir en el derecho a la vida privada, el derecho a la intimidad. Pero en mi opinión estos límites no pueden afectar a la esencia del derecho del enfermo ni justificar una intromisión frecuente del médico en el ámbito íntimo de la persona.

Por ejemplo, con relativa frecuencia los médicos de la Seguridad Social se encuentran con la actitud de determinados pacientes o usuarios del Sistema Nacional de la Seguridad Social que se niegan a recibir transfusiones de sangre en las intervenciones quirúrgicas prescritas por los facultativos médicos responsables clínicamente de su asistencia sanitaria. Dichos enfermos fundamentan su negativa en el derecho fundamental a la autonomía y responsabilidad individual que como persona le reconoce el Título I de nuestra Constitución, es decir, argumentan que forzarles a un determinado tratamiento lesiona su derecho a la integridad física y moral, a la libertad ideológica, religiosa y de culto, a la vida privada y, en definitiva, a su intimidad.

Varios autos del Tribunal Supremo (14 de marzo de 1979, 23 de diciembre de 1983 y 25 de enero de 1984) han abordado la cuestión desde el punto de vista también de la actividad médica, teniendo en cuenta que desde Hipócrates el deber profesional del médico es el de salvar por todos los medios a su alcance la existencia de los seres humanos. Así lo impone en nuestro país el propio Código de Deontología Médica y nuestro derecho positivo, en el artículo 489 bis del Código Penal, al castigar el 
abandono de ese deber por denegación de auxilio, así como el artículo 409, que penaliza el auxilio al suicidio.

En las citadas resoluciones el Tribunal se inclina a favor de los deberes de los médicos frente a los derechos del enfermo y, por lo tanto, justifica la aplicación forzosa del tratamiento partiendo del reconocimiento de que el médico que aplica dicho tratamiento está actuando eximido por el estado de necesidad reconocido en el artículo 8 del Código Penal.

El Alto Tribunal mantiene así que existe una primacía del derecho a la vida y a la salud, sobre la libertad religiosa, la intimidad o la integridad moral y la consideración de que la vida no es sólo un bien personal sino algo que se debe en gran parte a la familia y a la comunidad. Pues, desde un punto de vista penal, el derecho a la vida tiene un sentido de protección, pero no comprende la facultad de libre disposición de la propia vida de modo que pueda consentirse la muerte. La no penalización de la tentativa o frustración del suicidio no supone el derecho a disponer del propio cuerpo, sino que se fundamenta en razones de política criminal.

En el auto del Tribunal Supremo de 14 de marzo de 1979 se trataba de una mujer perteneciente a los Testigos de Jehová que habia rechazado recibir sangre; los médicos acudieron a un juez, el cual ordenó que se realizara la referida transfusión, aun con la oposición de la paciente. Ésta se querelló posteriormente contra el juez por presunta responsabilidad de un atentado contra la libertad religiosa (art. 205 del Código Penal), querella que no fue admitida por el Tribunal Superior por concurrir la eximente de estado de necesidad número 7 del artículo 8.․ y porque una inhibición podía haber dado lugar a responsabilidad penal por auxilio omisivo al suicidio, por incumplimiento del deber de socorro.

El Tribunal Supremo ha continuado declarando lícita la transfusión realizada a un miembro de esta confesión religiosa por orden del juez en otros autos: de 22 de diciembre de 1983 y de 25 de enero de 1984. No obstante, el interés de la decisión radica en que se utilizaron unos argumentos distintos pero complementarios de los del caso de 1979; se denunció un posible delito de coacciones y de atentado contra la libertad religiosa, alegando, respecto a éste último, que, según la Ley Orgánica sobre libertad religiosa, de 5 de junio de 1980, esta libertad encuentra sus límites, entre otros, en la "salvaguardia de la seguridad, de la salud y de la moralidad pública" (art. 3, párrafo 1.\%). El auto del Tribunal Constitucional de 20 de junio de 1984 resolvió el recurso interpuesto contra la resolución del Tribunal Supremo sosteniendo la misma argumentación jurídica. 
Los afectados también recurrieron en queja ante el Defensor del Pueblo, exponiendo la situación de inseguridad jurídica que se producía en los supuestos en los que el médico debe imponer un determinado tratamiento a un paciente que es rechazado por éste, y esta institución, estudiada la petición y las normas de la jurisprudencia aplicables, de acuerdo con los artículos 9,15 y siguientes de nuestra Ley Orgánica, tuvo que declararse incompetente para suplir el vacío normativo y la interpretación restrictiva que hasta ahora ha realizado la jurisprudencia. Por eso aprovecho estas consideraciones personales para proponer fórmulas que suplan lo que considero un vacío normativo y una interpretación anticuada e inadecuada de los derechos fundamentales a la intimidad y la integridad personal de los enfermos.

También parece que tienen preponderancia los mismos argumentos que los esgrimidos por el Tribunal Supremo en la Sentencia del Tribunal Constitucional que deniega el amparo solicitado por los presos en huelga de hambre (recurso de amparo n.o 443/1990), argumentos confirmados en sentencias posteriores. Por ejemplo, a partir de una interpretación gramatical de los artículos 53 de la Constitución Española y 49 de la Ley Orgánica del Tribunal Constitucional, se establece la separación entre valor superior y derecho fundamental y también se interpreta literalmente el deber que imponen a la Administración los artículos $3.4 \mathrm{~V}$ 45.1 b) de la Ley Orgánica General Penitenciaria de velar por la vida, integridad y salud de los internos. Según esto, el deber que tiene la Administración de asistir y ayudar a los internos puede, según la citada sentencia, dosificar la alimentación forzada, y en mi opinión el valor libertad tampoco permite considerar al enfermo siempre como incapaz, $y$ menos al que se niega explícitamente a someterse a un determinado tratamiento.

La doctrina que he reunido anteriormente justifica el tratamiento forzoso en base al conflicto entre el derecho a la autonomía del enfermo y la obligación del médico a velar por su vida. Este conflicto lo resuelve la jurisprudencia ponderando ambos bienes, dando primacía constitucional al deber del médico frente al derecho del paciente.

El facultativo, dicen, opta prescindiendo, o aun actuando contra la voluntad negativa expresada, aplicando el tratamiento o practicando la intervención que corresponda, amparado por el estado de necesidad de ser menor el daño producido que la muerte que se trata de evitar.

Sin embargo, personalmente no creo que estemos ante un conflicto, porque no es exigible responsabilizar a un tercero por no intervenir coactivamente para salvar a quien no desea ser salvado. A no ser que la enfermedad afecte o pueda afectar a terceros, como las enfermedades in- 
fecciosas, en estos supuestos el deber del médico a intervenir viene justificado por un interés más alto: la salvaguarda de la vida de terceros.

En estos casos, según la jurisprudencia, existe para el médico el deber de intervenir, porque de no hacerlo surge para el mismo una responsabilidad omisiva ante una situación de necesidad que requiere su intervención.

La pregunta fundamental es aquí si la negativa de una persona a recibir una transfusión de sangre o una alimentación forzosa, por razones personales, puede calificarse como suicidio. Los afectados insisten en dejar sentado que ni son suicidas ni ejercen el "derecho a morir» cuando se oponen a un tratamiento. La realidad es que quieren permanecer vivos; se trata de sujetos que quieren vivir, pero en otras condiciones.

El enfermo o accidentado que se niega a una intervención salvadora, aun a riesgo de su vida o su salud, se limita a aceptar una posible suerte debida a casos externos o naturales, a un peligro ya existente originado por accidente o enfermedad, pero no se provoca él mismo la muerte o la lesión, ni tiene voluntad de matarse o lesionarse, aunque tenga la voluntad de morir, y ello no convierte al sujeto en suicida, puesto que su propósito es aceptar un proceso natural que puede llevarle a la muerte o a la lesión.

Personalmente, tampoco creo que el argumento de la vida como bien social sea incuestionable, porque, como presupuesto general, creo que no es posible separar la dimensión social de un derecho de su dimensión individual, en mayor medida en aquellos derechos fundamentales cuyo ejercicio es personal e indelegable. La libertad y el derecho a la vida es presupuesto de todos los demás derechos y a partir de los mismos no se puede prohibir todo aquello de lo que uno puede abusar. El ejercicio del derecho a la vida privada o a la intimidad moral puede traer buenas y malas consecuencias; de lo contrario, no sería una libertad individual. Así, uno puede abusar de su privacidad hasta el extremo de arriesgar su vida, y no habría nadie con legitimación suficiente para obligarle o forzarle a hacerlo de otra forma. La libertad, y por lo tanto sus concreciones (derecho a la vida privada), supone el derecho a la autonomía del individuo para tomar por si solo las decisiones que mejor le convengan, siempre que no estén en juego derechos fundamentales de terceros o bienes y valores constitucionales, es decir, sin daño o menoscabo de los demás.

El derecho a la vida privada o a un ámbito de la vida privada, que no es más que el derecho a la autonomía y a la responsabilidad, es la libertad de que nadie que no sea uno mismo decida o imponga coactiva- 
mente lo que tengamos que hacer para conservar la salud, seguir viviendo o escapar del peligro. Visto así, el deber del Estado de asistir y ayudar a los enfermos, de velar por su seguridad $y$ vida, es garantizarle también su ámbito de libertad, es decir, garantizarle el ejercicio de aquellos derechos de los que sigue siendo titular. La necesidad de velar por la salud de los ciudadanos no permite considerar a todo enfermo como incapaz, $y$ menos a aquel que se niega explícitamente a seguir determinado tratamiento, aunque ello suponga riesgo para su propia vida.

El enfermo que tenga pretensión de no curarse, no se cura. Podemos intentar persuadirle, convencerle, incluso impedir por la fuerza que atente contra su salud cuando su capacidad de decisión libre está afectada; pero imponerle con todos los medios a nuestro alcance un determinado tratamiento es cuando menos difícil, y éticamente creo que, en una sociedad desarrollada y culta, inconveniente, porque desde la libertad nadie puede cometer un delito contra sí mismo, nadie puede tampoco ni tiene derecho a salvarnos de nosotros mismos, porque, estrictamente hablando, la cuestión no es cómo ser curado, sino cómo deseamos vivir. 